\title{
O conceito de Sistemas de Representações Sociais na produção nacional e internacional: uma pesquisa bibliográfica ${ }^{1}$
}

\author{
The concept of Social Representation Systems in national and international \\ production: a literature search
}

\author{
Lívia Botelho Félix ${ }^{2}$ \\ Danyelle Almeida de Andrade ${ }^{3}$ \\ Fernanda Siqueira Ribeiro ${ }^{4}$ \\ Clarissa Cristina Gonçalves Correia ${ }^{5}$ \\ Maria de Fátima de Souza Santos ${ }^{6}$
}

\begin{abstract}
RESUMO: Este artigo tem como objetivo apresentar uma pesquisa bibliográfica sobre o emprego do conceito de sistema de representações sociais (SRS) no âmbito da Teoria das Representações Sociais. Diversas bases de dados foram acessadas virtualmente (Scielo, BVS, Portal de Periódicos e de teses e dissertações da Capes, Google Acadêmico, e os periódicos da "Papers on Social Representation"), efetuando-se uma busca a partir dos seguintes termos: sistema, sistema de representação social, sistema representacional, e suas variações em inglês e no plural. Foram incluídos na análise 37 artigos e 7 teses/dissertações publicados entre 1993 e março de 2015 . Através da análise documental, organizou-se o corpus em quatro categorias principais: "SRS como conjunto de representações sociais", "SRS como conjunto de conhecimentos", "SRS como sinônimo de representações sociais", e "Noções dispersas". O uso do conceito de SRS como conjunto de representações sociais foi mais frequente, seguida pela categoria "noções dispersas". Observou-se que algumas produções analisadas apresentam aprofundamentos do ponto de vista teórico e/ou metodológico. Na maioria, entretanto, o conceito de SRS não é utilizado como objeto ou tema de estudo, emergindo com pouco destaque nos textos. Considerase que contribuições podem ser feitas no sentido de elucidar os modos como os sistemas representacionais se caracterizam e se constituem, bem como as implicações que o olhar sobre o(s) objeto(s), a partir do ponto de vista de SRS, pode acarretar na compreensão dos fenômenos sociais estudados.
\end{abstract}

Palavras-chave: teoria das representações sociais; sistema de representações sociais; sistema representacional; pesquisa bibliográfica.

ABSTRACT: This article attempts to present a literature search on the use of the notion of social representation system (SRS) under the Social Representation Theory (SRT). Several databases were accessed virtually (Scielo, BVS, Journal Portal and theses and dissertations from Capes, Google Scholar, and the journals of the "Papers on Social Representation"). A search was realized starting with the following terms: system, system of social representation, representational

\footnotetext{
${ }^{1}$ Agradecemos aos integrantes do grupo de pesquisas em representações sociais do Laboratório de Interação Social Humana (LABINT - UFPE), pelas leituras e contribuições tecidas na elaboração deste artigo.

2 Psicóloga. Mestra em Psicologia. Doutoranda do Programa de Pós-graduação em Psicologia da Universidade Federal de Pernambuco (UFPE) - Recife, PE, Brasil. E-mail: liviabotelhofelix@hotmail.com.

3 Psicóloga. Mestra em Psicologia. Doutoranda do Programa de Pós-graduação em Psicologia da Universidade Federal de Pernambuco (UFPE) - Recife, PE, Brasil.

${ }^{4}$ Psicóloga. Doutora em Psicologia pela Universidade Federal de Pernambuco (UFPE) - Recife, PE, Brasil.

${ }^{5}$ Psicóloga. Mestra em Psicologia. Doutoranda do Programa de Pós-graduação em Psicologia da Universidade Federal de Pernambuco (UFPE) - Recife, PE, Brasil.

${ }^{6}$ Doutora em Psicologia pela Université de Toulouse II - Le Mirail, França. Professora titular do Departamento de Psicologia e da Pós-graduação em Psicologia da Universidade Federal de Pernambuco (UFPE). Bolsista de produtividade do CNPQ Recife, PE, Brasil.
} 
system, and variations in English and in plural. The analysis included 37 articles and 7 theses / dissertations published between 1993 and 2015. Through documental analysis, the corpus was organized into four main categories: "SRS as a set of representations", "SRS as a body of knowledge" "SRS as a synonym of social representations", and "Scattered notions". The use of SRS concept as a set of social representations prevailed, followed by scattered notions category. Some productions present insights of theoretical/methodological point of view. At most, however, the concept of SRS isn't used as an object or subject of study, emerging with low emphasis in the texts. Those contributions can be made to elucidate the ways in which representational systems are formed and characterized. Furthermore, the implications of consider the object(s) from the SRS point of view can result in a better comprehension of social phenomenon in case.

Keywords: theory of social representations; system of social representations; representational system; bibliographic search.

\section{Introdução}

Este artigo tem como proposta apresentar uma análise acerca do uso do conceito de sistemas de representações sociais (SRS) no âmbito da Teoria das Representações Sociais (TRS). Para tanto, parte de uma pesquisa bibliográfica em bancos de dados nacionais e internacionais, a fim de identificar e refletir sobre as principais referências, tendências e possíveis lacunas no emprego desse conceito.

Reconhece-se que a teoria teve como marco o lançamento da obra "La psychanalyse, son image et son public" em 1961. Nesse trabalho, Moscovici (1961/2012), no âmbito da Psicologia Social, investigou como os conhecimentos da Psicanálise eram apropriados pela população em diferentes setores do público francês. O autor conceitua o fenômeno das representações sociais e se debruça sobre a investigação dos processos pelos quais essas são construídas.

A TRS é um aporte teórico que estuda o fenômeno das representações sociais (RS), entendido como as teorias que são produzidas no senso comum, ou seja, como as pessoas e os grupos sociais, no curso de suas vidas cotidianas, constroem saberes sobre si mesmas, sobre os outros e sobre os diversos objetos sociais que lhe são relevantes. Nesse sentido, o objeto social investigado pela TRS encontra-se no trânsito da interação sujeito - grupo social, sendo transformado mutualmente por essa relação. Segundo Jovchelovitch (2007), a teoria busca explicar "como os saberes sociais são produzidos e transformados em processos de comunicação e interação social" (p. 87). As representações sociais são como moduladoras do pensamento, regulando a dinâmica social, em meio aos conflitos e convergências que ocorrem na mudança social. Desta forma, três aspectos importantes caracterizam as representações sociais: a comunicação, a (re)construção do real e o domínio do mundo. A comunicação funciona como um código de trocas construído entre as pessoas, que dão nome e classificam as coisas no mundo social (Almeida, 2001).

A (re)construção do real é o movimento dinâmico entre comunicação e representação que reconstrói a realidade do dia a dia. Desta forma, as representações sociais servem como guias de interpretação e organização dessa realidade. Além disso, elas funcionam como um conjunto de conhecimentos sociais, para que o sujeito se situe e domine o mundo na prática (Almeida, 2001). As representações sociais, portanto, tem funções específicas, como a de orientar condutas, explicar a realidade social, justificar tomadas de posição, além de definir identidades, ao mesmo tempo em que preserva as particularidades dos grupos (Moscovici, 2003; Santos, 2009). Trata-se de uma perspectiva 
que compreende o sujeito como ativo na construção e reconstrução coletiva do conhecimento, que se dá através das trocas comunicacionais e do seu pertencimento grupal.

No decorrer de sua obra, Moscovici também se debruçou em compreender como as representações sociais são construídas, destacando, nesse sentido, dois processos fundamentais: a ancoragem e a objetivação. A ancoragem seria a incorporação ou assimilação de novos elementos de um objeto em um sistema de categorias já familiar ao sujeito, disponíveis na memória (Moscovici, 2003). Para o autor, o indivíduo integra o objeto da representação a um sistema de valores próprio, nomeando-o e classificando-o, em função da relação que já existe na sua inserção social (Trindade, Santos \& Almeida, 2011). E de forma inseparável, a objetivação busca transformar o que era abstrato em concreto, relacionando com o mundo físico o que já estava na mente, unindo a ideia de não familiaridade com a de realidade. Refere-se à organização dos elementos constituintes da representação, possibilitando o caminho para que os elementos tenham materialidade (Moscovici, 2003).

A partir dos postulados de Moscovici sobre a TRS, desenvolveram-se três abordagens teórico-metodológicas distintas para estudar o fenômeno das RS. A abordagem processual (ou culturalista), fomentada por Denise Jodelet, compreende as RS como o estudo dos processos e dos produtos através dos quais os sujeitos e os grupos constroem e significam o mundo, integrando as dimensões sociais e culturais com a história. Para Jodelet, um estudo em Representações Sociais deve abarcar os discursos dos grupos que criam RS de um dado objeto; os comportamentos e práticas sociais que se expressam nas RS; o exame dos documentos e registros que institucionalizam os discursos e práticas do grupo; e as interpretações a eles dados pelos meios de comunicação, os quais influenciam na manutenção e transformação das RS (Almeida, 2005).

Por sua vez, a abordagem estrutural de Jean-Claude Abric se debruça sobre os conteúdos das RS e a forma como eles se organizam, considerando pontos como a estabilidade e a mudança, e sua relação com a prática social do grupo em questão (Jodelet, 2001). De acordo com Abric (1998), existe um núcleo central em torno do qual a RS se estrutura. Tal núcleo seria determinado pela natureza do objeto em estudo, pela forma como o grupo se relaciona com ele, e pelo sistema de valores e normas sociais que compõem o meio ideológico vigente no momento. É o núcleo central o elemento mais estável da representação e, por isso, resistente às mudanças, mantendo a continuidade dos elementos da RS mesmo em contextos móveis e evolutivos. Dessa forma, quaisquer modificações no núcleo central alteram a RS. Além do núcleo central, existem os demais elementos constituintes da RS, percebidos em torno do primeiro e nomeados de elementos periféricos. São esses os componentes mais acessíveis, dinâmicos e concretos da representação; integram as experiências cotidianas e são mais individualizados e localizados.

A terceira abordagem é denominada de societal. Conforme Almeida (2009), essa abordagem foi fundada na Escola de Genebra, liderada por Willem Doise. No decorrer de sua trajetória acadêmica, o teórico se debruçou sobre o aporte das representações sociais, por considerar este um quadro profícuo para a construção de uma psicologia societal que imbricasse o estudo dos sistemas cognitivos aos sistemas relacionais e societais. Nesse sentido, propôs a articulação de explicações de ordem individual e societal, de modo a evidenciar que os processos subjacentes ao funcionamento dos indivíduos em sociedade são orientados por dinâmicas sociais de diferentes ordens (interacionais, posicionais e/ou crenças e valores) (Almeida, 2009). Sendo assim, destaca-se que uma das principais 
contribuições da abordagem societal é a proposição de investigações que visem à integração de distintos níveis de análise no estudo dos fenômenos e das representações sociais.

Outro aspecto da abordagem formulada por Doise se refere ao interesse sobre os conceitos de sistema e metassistema propostos por Moscovici (1961/2012). Para este, em todo o pensamento que objetiva 'apreender categorias' atuam dois sistemas cognitivos: um sistema operacional faria associações, inclusões, discriminações, deduções; enquanto que um metassistema controlaria, verificaria, selecionaria por meio de regras lógicas ou não, os conteúdos elaborados pelo primeiro, retrabalhando-os. Nesse último, as relações que o compõem seriam primordialmente normativas (Moscovici, 1961/2012). Segundo Doise (2011), é tarefa fundamental dos psicólogos sociais se deterem sobre as relações entre as normas sociais e os funcionamentos cognitivos que operam nas representações sociais, mais especificamente, sobre como se dariam as atualizações das regulações feitas pelo metassistema social no sistema cognitivo.

É nesse amplo e complexo cenário social da inter-relação entre fenômeno social, objeto e sujeito, que se insere a proposição teórica e metodológica da TRS. Desta forma, a teoria tem um amplo alcance sobre os fenômenos na sociedade, o que suscita tentativas de sentidos baseadas no conhecimento construído pelo(s) grupo(s) o(s) qual(is) pertencemos, a partir da teia das relações sociais, comunicacionais, cognitivas e afetivas (Arruda, 2009).

O arcabouço teórico e metodológico da TRS vem embasando diferentes pesquisas e estudos no Brasil, não apenas no campo da Psicologia Social, como também nas áreas de Educação, Enfermagem, Serviço Social, entre outras, diante dos mais diversos, relevantes e multifacetados fenômenos sociais (Sá, 1998). Jodelet (2011) destaca a produção brasileira no cenário da TRS quando situa que, diante da sua amplitude geográfica, em 2010 apenas cinco estados (entre 26 estados nacionais e o Distrito Federal) não possuíam representantes no campo da TRS. Esse quadro coloca o Brasil em destaque em termos de vitalidade do campo, à frente de outros países da América do Sul, América do Norte e até mesmo da Europa. A autora ainda ressalta a existência de um "movimento brasileiro", no que concerne às pesquisas realizadas neste país a partir da TRS. Essa distinção é possível tendo em vista que no Brasil, na maioria das vezes, essa perspectiva teórica é utilizada como um instrumento para conhecer a realidade social e intervir sobre ela, contribuindo para o manejo dos problemas relacionados aos domínios de sua aplicação.

Sobre o desenvolvimento e expansão da TRS é válido destacar a recente pesquisa de Wachelke, Matos, Ferreira e Costa (2015), os quais investigaram produções acadêmicas desta área, publicadas em periódicos científicos. A busca, realizada entre os meses de agosto e setembro de 2013, localizou 2.526 resumos de artigos publicados. A partir desses foi possível identificar uma predominância de primeiros autores provenientes do continente sul-americano e europeu, sendo o Brasil identificado como o líder atual em termos da localização do primeiro autor, seguido pela França. Em suas conclusões, os autores puderam constatar a importância da produção sul-americana (e brasileira) sobre representações sociais publicada em periódicos científicos.

Algumas pesquisas desenvolvidas no Laboratório de Interação Social Humana da Universidade Federal de Pernambuco (LABINT - UFPE) corroboram com esses achados, ao revelarem a crescente utilização desse referencial teórico em cenário regional e nacional. Visando compreender quais as vertentes teóricas privilegiadas no desenvolvimento das pesquisas em Psicologia Social no Brasil, Santos et al. (2013), analisaram 550 artigos 
publicados nos periódicos da área da Psicologia avaliados em 2012 pela CAPES com Qualis A1, A2 e B1 no período de 2007 a 2011. Dentre os resultados apresentados, a TRS se destaca como referencial em $18 \%$ da produção nacional em Psicologia Social. Santos, Morais e Acioli Neto (2012), por sua vez, realizaram uma pesquisa bibliográfica da produção em TRS nos Programas de Pós-Graduação do estado de Pernambuco no período de 1998 e 2008. Nesse estudo, os autores identificaram o uso dessa perspectiva como aporte teórico em 13 (treze) áreas de conhecimento distintas (a saber, Psicologia, Educação, Serviço Social, Hebiatria, Geografia, Letras, Desenvolvimento Urbano e Meio Ambiente, Sociologia, Antropologia, Gestão Ambiental, História, Comunicação e Nutrição), representando 3\% das produções dos programas de pós-graduação do estado.

Além do interesse em estudos do tipo revisão bibliográfica voltados para a análise da produção acadêmica em Psicologia Social e, mais especificamente, em relação ao aporte teórico das representações sociais (Santos et al., 2013; Santos, Morais \& Acioli Neto, 2012), nas mais recentes pesquisas em TRS desenvolvidas pelo laboratório, começou-se a observar resultados que indicavam fortes relações entre diferentes objetos de representações sociais. Nesse sentido, Santos, em 2011, propôs um projeto de pesquisa sobre sistemas de representações sociais, o qual tinha como objetivo principal investigar ligações possíveis entre diversos objetos articulados em torno da representação social de família.

Ao longo dos estudos desenvolvidos pela própria autora e por outros pesquisadores, ela observou que alguns objetos pareciam suscitar representações intrinsecamente relacionadas a outras representações sociais. Seriam importantes, então, maiores investigações sobre o conceito à medida que, segundo a proposição de Jodelet (1984) apontada por Santos (2011), estudar representações sociais de objetos distintos, em diferentes grupos, contribuiria para uma compreensão melhor dos princípios subjacentes à atualização dessas representações.

Família seria um objeto de representação social privilegiado para se estudar possíveis sistemas de representação social por ser 'central' na sociedade brasileira e ser uma importante referência nas etapas do desenvolvimento. Parece haver, ao se pensar família, um conjunto de diferentes objetos de representação social que se imbricam, como as representações sociais de homem, mulher, sexualidade, filho/a, mãe, pai, entre outros (Santos, 2011).

Diante disso, surge o interesse de saber de que forma a literatura da área vem concebendo e tratando o conceito de sistema de representações sociais. Alguns autores, como Camargo e Wachelke (2010), Wachelke e Contarello (2011) e Wachelke (2011) apresentam referências dos primeiros autores que citaram o termo. Segundo tais estudos, a ideia de SRS já aparece nos primórdios da TRS, quando Moscovici (1961/2012) a considera como uma clara derivação do processo de ancoragem, indicando que, de fato, as representações sociais se organizam em redes, embora geralmente sejam estudadas separadamente.

Ainda segundo Moscovici (1961/2012, p. 58), "para penetrar no universo de um indivíduo ou de um grupo, o objeto entra numa série de relacionamentos e articulações com outros objetos que já estão lá e dos quais ela empresta as propriedades e acrescenta as suas próprias". Por meio do estudo das representações sociais da Psicanálise na França, o autor supõe que a ancoragem coloca o novo objeto numa rede de significações, a qual foi formada em torno de uma ciência, transformando assim, a objetividade científica em fato social. 
Assim, "a sociedade torna o objeto social um instrumento do qual pode dispor e esse objeto é colocado numa escala de preferência nas relações sociais existentes" (Moscovici, 1961/2012, p. 156).

De acordo com Camargo e Wachelke (2010), Di Giacomo, em publicação de 1980, foi um dos primeiros a estudar a interação entre conjuntos de representações sociais. $\mathrm{O}$ autor demonstrou que os resultados de um protesto organizado por estudantes poderiam ser explicados pelas representações que esse público compartilhava sobre si mesmo, sobre os líderes do movimento e sobre as estratégias utilizadas nos protestos. Concluiu que à medida que os estudantes consideravam diferenças em relação à sua cultura e a do comitê organizador do protesto, eventualmente esse não teria adesão em longo prazo. Segundo Di Giacomo (1980 citado por Camargo \& Wachelke, 2010), essa conclusão não seria possível, caso ele tivesse estudado tais representações sociais separadamente.

Jean Paul Codol, em 1984, trouxe a ideia de que o sistema de representações estaria relacionado ao processo de ancoragem, entendido por ele como algo que denota a interdependência, no universo cognitivo dos indivíduos, entre as representações de diferentes objetos que coexistem na mesma situação. $O$ autor realizou uma série de estudos, de cunho experimental, com estudantes, no intuito de investigar os elementos representacionais em torno dos quais o grupo se organiza: a tarefa, os outros, o grupo e si mesmos. A partir de suas pesquisas, Codol mostrou também que, ao alterar a representação de qualquer elemento constituinte do sistema, é bastante perceptível a modificação da forma como cada membro do grupo representa todos os outros elementos envolvidos na situação. Contudo, os experimentos realizados, apesar de produzirem claras evidências da existência de um sistema representacional nessas situações de grupo, ainda não indicaram a força ou o tipo de relação que as representações em questão estabelecem entre si (Codol, 1984).

Nesse âmbito, o teórico se baseou nos experimentos de Asch sobre a teoria do traço central, o qual postulava que, em uma estrutura cognitiva, o elemento mais central é aquele de maior correlação com outros elementos. Assim sendo, Codol considerou que, em um sistema de representações, quanto maior a medida das correlações com outras representações, mais central seria uma representação em particular. Assim, sua pesquisa sugeriu que a representação mais central é a de si mesmo, seguida pela de tarefa, do grupo e dos outros (Codol, 1984).

Em 1993, Breakwell também considerou que as representações sociais estão organizadas em redes, como consequência do processo de ancoragem, estando inevitavelmente ligadas umas às outras, devendo essa ligação ser levada em consideração nos estudos de representação social. Segundo Camargo e Wachelke (2010) e Wachelke e Contarello (2011), Rouquette, em 1994, endossou a ideia de que as representações sociais interagem entre si, justificando que objetos de representação não são independentes uns dos outros, porque não há uma definição natural das fronteiras entre as representações sociais, uma vez que são resultados de pesquisas e de decisões. Além disso, as representações sociais estariam inter-relacionadas no decorrer dos acontecimentos históricos, e por isso, herdam as cargas de eventos passados.

Garnier, em 1999, realizou um estudo com crianças a fim de entender como se daria a gênese das representações sociais. Para tal, entrevistou dois grupos de crianças em idades e escolas diferentes acerca dos objetos "corpo", "saúde" e "meio ambiente". Percebeu 
então, que as representações sociais desses objetos, chamados 'complexos', se encontravam em articulação e mantinham entre si dadas relações, no plano de suas estruturas, que constituíam um sistema representacional. Ela observou que tais objetos se situavam em um mesmo universo, concernente às relações humanas.

Em 2001, Santos, Novelino e Nascimento, consideraram que as diversas representações sociais construídas pelas coletividades sobre distintos objetos estão conectadas umas com as outras, constituindo sistemas em constante transformação, de acordo com o dinamismo da realidade social. De acordo com as autoras, a maternidade não pode ser concebida apenas como um fenômeno biológico, mas se ancora em uma rede de significados, num "sistema de códigos articulado e estruturado ideologicamente, indissociável das concepções correntes de homem, mulher, família, criança" (Santos, Novelino \& Nascimento, 2001, p. 270).

Observa-se que a relevância do conceito de sistema de representações sociais vem sendo reconhecido no âmbito do aporte teórico das representações sociais. Assim como apontando por Wachelke (2005), não se trata de algo novo no estudo da TRS. O autor argumenta, contudo, que esse conceito ainda é pouco explorado e não apresenta contornos bem delimitados, de forma que possibilite o emprego de outras nomenclaturas, como "representações que regulam outras representações, matrizes representacionais ou algum nome semelhante" (p. 318). A partir das reflexões apresentadas, questiona-se: como esse conceito vem sendo trabalhado nas publicações em TRS? Buscando explorar essa questão objetiva-se com este trabalho a realização de uma pesquisa bibliográfica sobre o uso do conceito de sistemas de representações sociais (SRS) no âmbito da Teoria das Representações Sociais (TRS).

\section{Método}

Baseado em Lima e Mioto (2007), este trabalho se configura como uma pesquisa bibliográfica realizada com o intuito de fundamentar teoricamente um determinado objeto de estudo e contribuir com elementos que subsidiam análises futuras. A pesquisa bibliográfica emerge como procedimento metodológico de suma importância na produção do conhecimento científico, sobretudo no tocante a temas pouco explorados. Segundo as autoras, trata-se de:

um movimento incansável de apreensão dos objetivos, de observância das etapas, de leitura, de questionamentos e de interlocução crítica com o material bibliográfico que permite, por sua vez, um leque de possibilidades na apreensão das múltiplas questões que envolvem o objeto de estudo (Lima \& Mioto, 2007, p. 44).

Por isso, demanda-se a descrição minuciosa do tipo de pesquisa, das fontes, instrumentos de coleta e análise de dados, apresentando "as lentes" que orientarão o processo de investigação (Lima \& Mioto, 2007).

\section{Fontes}

As buscas foram realizadas nas bases de dados do Portal de Periódicos e Banco de Teses e Dissertações da Capes, no Scielo e na Biblioteca Virtual de Saúde (BVS), buscando cobrir a produção científica nacional acerca do conceito de SRS. Decidiu-se estender as buscas às publicações do periódico "Papers on Social Representation", pois essa é uma 
revista específica da área, de referência internacional, dedicada a promover o desenvolvimento da TRS. Dessa forma, poder-se-ia, preliminarmente, compreender também como vem se desenvolvendo o conceito de SRS no país, frente às produções em contextos internacionais.

Assim, foram analisados 37 artigos científicos publicados em periódicos nacionais e internacionais entre 1993 e 2014, sendo 12 deles selecionados a partir de bases de dados nacionais e 25 encontrados no referido periódico. Além destes textos, foram analisadas 7 dissertações/teses brasileiras produzidas entre 2009 e 2015.

\section{Procedimentos de coleta}

As buscas pelas produções foram realizadas virtualmente entre março a abril de 2015. Nesse período, efetuou-se uma busca nas referidas bases de dados a partir dos termos sistema de representação social, sistema representacional e suas variações em inglês e no plural. Não foi utilizado nenhum recorte temporal para selecionar essas fontes, buscando, assim, abarcar o maior número de publicações possíveis. Com base nos resultados encontrados na busca, os textos foram lidos e selecionados a partir dos seguintes critérios de inclusão: apresentar a TRS como aporte teórico, e, concomitantemente, tratar do conceito de SRS especificamente. Foram, assim, excluídos os artigos que não possuíam esse referencial teórico e/ou aqueles cujo termo "sistema" se referia a outra questão/assunto, como por exemplo, sistema único de saúde, sistema educacional, sistema central, sistema periférico, dentre outros. Essa diferenciação foi necessária tendo em vista que a ferramenta de busca das referidas bases não filtrava a expressão exata.

É importante ressaltar que, como a revista Papers on Social Representation não possui uma ferramenta similar, a busca foi realizada de forma manual, abarcando todos os volumes e números disponíveis no site. Isto é, realizou-se o download dos artigos e, por se tratar de um periódico internacional em representações sociais, utilizou-se as palavras "sistema", "system" ou "système" como localizadores em cada um dos artigos, a depender do idioma em questão. Dessa forma, almejou-se também contemplar as possíveis variações que o termo poderia assumir. Apesar dos diferentes caminhos utilizados para a seleção dos textos (de forma manual ou fazendo uso de ferramentas de buscas dos referidos sites e portais), buscou-se alcançar o mesmo objetivo: verificar a ocorrência do termo SRS nas publicações nacionais e na revista internacional especializada na área.

No que concerne às teses e dissertações, a partir dos mecanismos de busca disponíveis, os referidos termos foram procurados nos títulos, resumos e palavras-chave das pesquisas disponíveis no banco de dados. Como critério de inclusão na análise foram selecionados apenas os trabalhos que utilizassem o aporte teórico da TRS, resultando em apenas 02 produções (01 tese e 01 dissertação). Diante da escassez e/ou da dificuldade de localizar os trabalhos produzidos ao nível da pós-graduação nacional que se utilizavam do referido conceito, outros trabalhos foram incluídos no corpus de análise. Com isto, buscouse atender à regra da pertinência, quanto à organização da análise (Bardin, 1977/2011), que preconiza a retenção de documentos adequados e que corresponderam ao objetivo que suscita a análise. Assim, além desses, foram acrescidos à pesquisa cinco outros trabalhos, sendo um deles (tese) produzido pelo mesmo grupo de pesquisa das produções anteriormente encontradas e outros quatro (dissertações) desenvolvidos pelo grupo de pesquisa do qual as autoras deste artigo fazem parte. Esses últimos trabalhos inclusos, por 
se tratarem de publicações mais recentes (após 2012), ainda não se encontravam disponíveis no referido portal na ocasião da coleta de dados. No total foram analisadas 7 (sete) produções publicadas entre 2009 e 2015.

\section{Procedimento de análise}

Após o levantamento do material, a análise foi realizada a partir de três etapas principais:

1) Construção e posterior classificação dos textos em uma grade de análise que continha as seguintes informações: Tipo (Artigo/ Tese/ Dissertação); Título; Publicação (Revista/PPG); Ano; Autores; Palavras-chave; Link de acesso; Resumo; Natureza (Empírica/Teórica); Recorte dos trechos que incluem o termo "sistema"; Discussão/articulação com outros conceitos, temas e dados da pesquisa; Referências que embasam o conceito; e Centralidade do conceito de SRS para o trabalho;

2) Leituras e aproximações sucessivas do material;

3) Categorização das noções de SRS apresentadas.

Lima e Mioto (2007) explicitam e delimitam possibilidades de análise na pesquisa bibliográfica. Segundo as autoras, a utilização do desenho metodológico circular ou de aproximações sucessivas, tal como realizado,

permite, através da flexibilidade na apreensão dos dados, maior alcance no trato dialético desses dados, pois o objeto de estudo pode ser constantemente revisto, garantindo o aprimoramento na definição dos procedimentos metodológicos, como também a exposição mais eficiente do percurso de pesquisa realizado (Lima \& Mioto, 2007, p. 44).

A análise realizada foi do tipo documental, que segundo Bardin (1977/2011) consiste numa operação de tratamento de documentos com o objetivo de reapresentar, por intermédio de procedimentos de transformação, as informações contidas naqueles. Ainda segundo a autora, a análise documental tem a finalidade de facilitar o acesso e armazenar o máximo de informação com o máximo de pertinência, englobando aspectos quantitativos e qualitativos respectivamente. Nesse sentido, após leitura exaustiva do material, realizou-se o recorte de informações e divisão do corpus em categoriais segundo o critério da analogia. Embora a análise documental se assemelhe à clássica análise de conteúdo, apresenta algumas distinções fundamentais, sobretudo em relação às fontes e funções. Enquanto a primeira trabalha com documentos e tem por objetivo a representação condensada de informações para consulta e armazenamento, a segunda visa à manipulação de mensagens (conteúdo e expressão desse conteúdo) com o intuito de realçar "indicadores que permitam inferir sobre outra realidade que não a da mensagem" (Bardin, 1977/2011, p. 52).

Na sequência, a análise realizada será apresentada seguindo a proposta de Lima e Mioto (2007): em categorias conceituais exemplificadas com citações dos autores julgadas pertinentes para ilustrar o tema/conceito em questão.

\section{Resultados e discussão}

Em termos quantitativos, os resultados encontrados apontam para o crescente uso do conceito nos últimos 5 (cinco) anos em todos os tipos de publicação. $O$ gráfico abaixo ilustra a distribuição das produções quanto ao ano e tipo de publicação. É possível observar que 
entre 1993 e 2008 há o predomínio da publicação de artigos (com frequência de 1 (um) por ano), sendo que somente a partir de 2009 foi possível localizar produções referentes a teses e dissertações, assim como publicações mais frequentes de artigos. Ressaltando novamente que, dos 37 artigos localizados e analisados, 25 foram publicados na revista Papers Social Representation.

No tocante ao conjunto de teses e dissertações, é necessário apontar e ponderar como uma possível limitação do estudo, a dificuldade de localizar esse material a partir da ferramenta de buscas do sistema, assim como o acréscimo deliberado de produções acessíveis às autoras. Esse contexto de produção dos dados evidentemente se relaciona com a distribuição crescente verificada no gráfico a seguir.

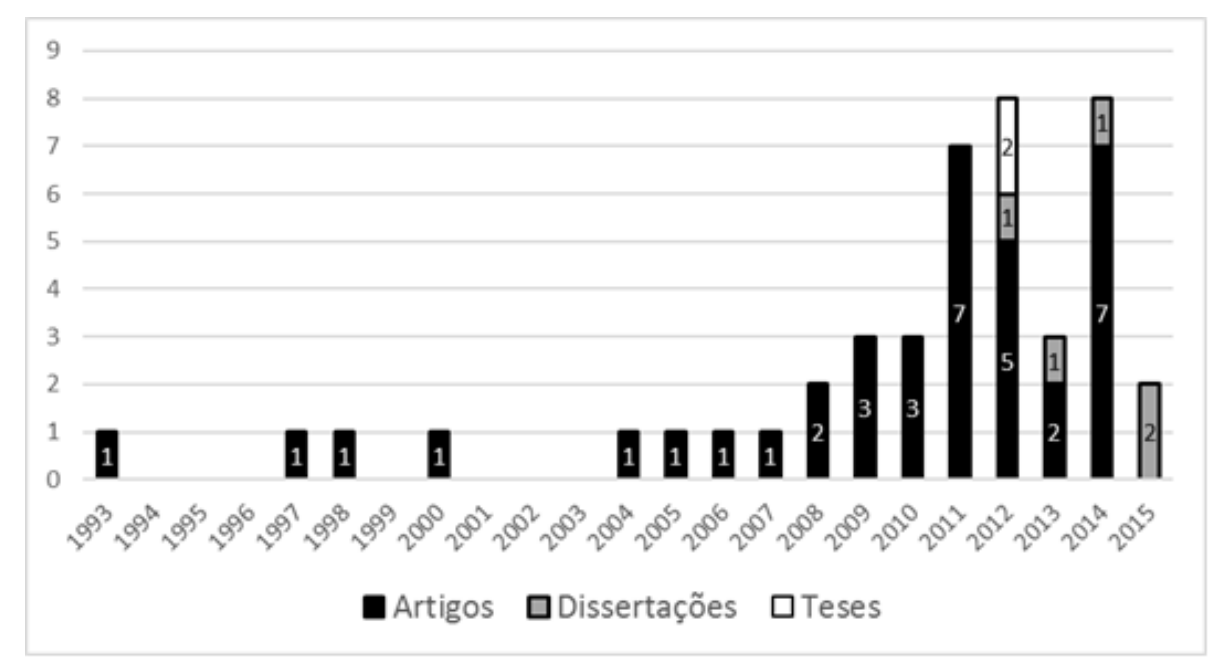

Figura 1 - Distribuição das produções quanto ao ano e tipo de publicação

A partir da análise do corpus, classificou-se os resultados em 04 (quatro) categorias, a saber: 1) SRS como conjunto de conhecimentos; 2) SRS como conjunto de representações sociais; 3) SRS como sinônimo de representações sociais; 4) Noções dispersas. A imagem a seguir apresenta as referidas categorias, bem como sua frequência:
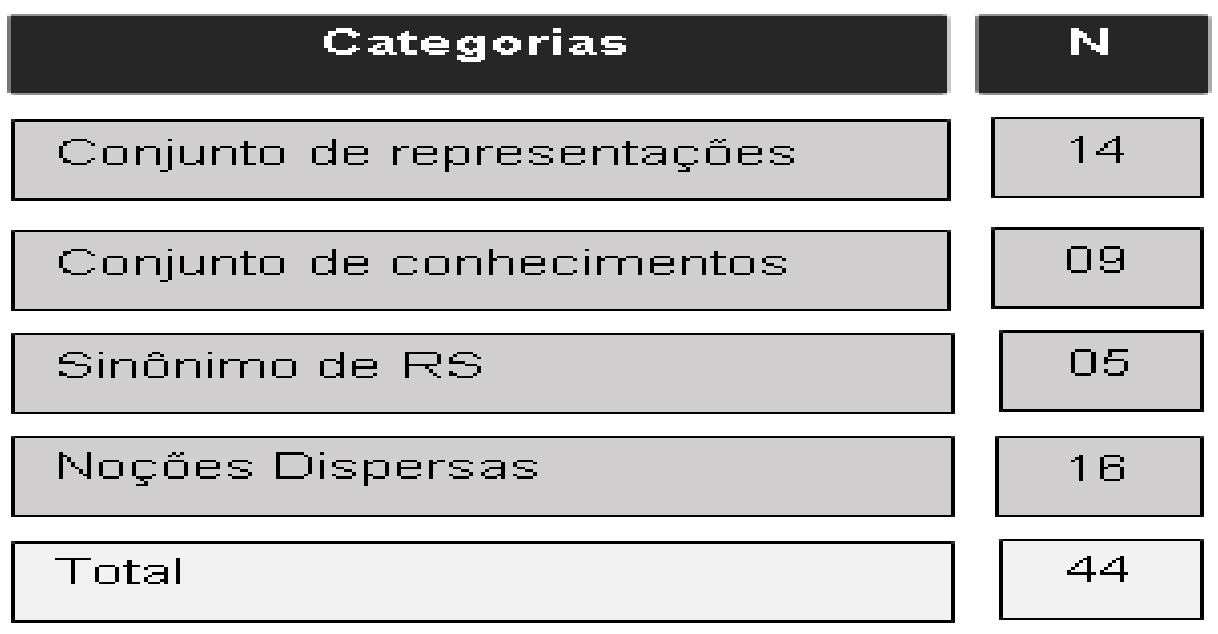

Figura 2 - Categorias de análise 
Vale destacar que, a descrição e discussão dessas categorias serão apresentadas priorizando-se uma ordem decrescente quanto à complexidade do conteúdo identificado, em termos de fundamentação e aprofundamento no estudo do conceito de SRS, em detrimento da quantidade de trabalhos classificados por categoria.

\title{
SRS como conjunto de representações sociais
}

Averiguou-se que boa parte das produções analisadas (14) aborda o conceito de SRS a partir de um conjunto de representações sociais. Nesses casos, o sistema diz respeito a articulações entre representações e/ou objetos sociais, podendo ser identificado a partir do compartilhamento de elementos, como no trecho abaixo:

\begin{abstract}
What this comes to show is that representations are never singular, but come in complex systems that include the representation itself alternative or counter representations, a representation of the in-group and the out-group holding these representations and also an appreciation of the power relations between groups and how they are reflected in the distribution and acceptance of representations. (Glaveanu, 2009, p. 13) ${ }^{7}$.
\end{abstract}

Camargo e Wachelke (2010), por exemplo, caracterizam as relações entre as representações sociais de AIDS, envelhecimento e corpo, através de uma pesquisa exploratória. Para tanto, os autores aplicaram questionários com 1.118 estudantes acerca de um dos referidos objetos, solicitando a escolha de 03 (três) das 12 (doze) palavras extraídas da literatura mais fortemente relacionadas ao objeto em questão, seguida de uma justificativa sobre a escolha.

A partir da articulação entre dois conceitos teóricos específicos, o de sistema representacional e o de arquitetura do pensamento social, os autores explicitam que as contribuições principais do estudo contemplam os níveis teórico, metodológico e aplicado, simultaneamente. Nos três níveis, o conceito de sistema representacional é diretamente apontado. Em termos teóricos, os autores identificam a tentativa de associação entre o fenômeno das representações sociais e as redes de pensamento social, de modo que o conceito de SRS é indicado como subjacente às zonas de intersecção das representações sociais de objetos distintos. Ademais, a pesquisa propôs, em nível metodológico, caracterizar as relações entre diferentes representações sociais por meio da elucidação dos elementos comuns a essas. Por fim, em relação às aplicações, os autores consideram que tais achados poderiam beneficiar a caracterização de interações entre representações sociais que não são investigadas diretamente, como as representações sobre vida, saúde e sexo, contribuindo assim, para a compreensão sobre a lógica do pensamento social relativos à AIDS e à epidemia de HIV.

Em outra publicação, Wachelke e Contarello (2011) se propuseram a analisar as relações entre diferentes representações sociais em dois níveis: inter e intra representações. No primeiro nível, os autores identificam os elementos que interseccionam as representações investigadas, enquanto que o segundo se debruça sobre as relações estabelecidas entre os elementos das representações. Os autores elegem a representação social de envelhecimento como organizadora do SRS e a ela adicionam outros seis objetos na

\footnotetext{
7 O que isso mostra é que representações nunca são singulares, mas um sistema complexo que inclui a própria representação, representações alternativas ou opostas, a representação do intra grupo e do "out" grupo que suportam essas representações e também a apreciação das relações de poder entre grupos e como elas se refletem na distribuição e aceitação das representações. (Glaveanu, 2009, p. 13, tradução e aspas nossas).
} 
investigação, objetos estes que a literatura aponta estarem relacionados ao envelhecimento (tempo, morte, saúde, corpo, trabalho e família). Participaram desse estudo 151 graduandos de uma universidade italiana, que responderam a um questionário de associação livre, o qual continha os objetos supracitados como palavras indutoras. Seguidamente, os participantes deveriam identificar se suas respostas eram positivas, negativas ou neutras e, por fim, avaliar pares dos objetos sociais quanto à sua proximidade, segundo uma escala de quatro pontos que iam do "distante" ao "perto".

Wachelke e Contarello (2011) deram continuidade à discussão sobre SRS do trabalho anteriormente citado (Camargo \& Wachelke, 2010), e adicionaram novas considerações. A partir de Flament e Rouquette (2003 citado por Wachelke \& Contarello, 2011), as relações de coordenação entre as representações sociais podem ser de conjunção ou disjunção, de acordo com similaridade do núcleo central. Na disjunção não há interseção entre os núcleos centrais, em relação aos elementos que os constituem; enquanto que na conjunção, há. Wachelke e Contarello (2011) apontam outra possibilidade, ressaltando que esta não é diretamente identificada por Flament e Rouquette (2003), que seria o caso de um objeto social que se refere a uma das representações, ser ele mesmo um elemento central ou periférico na estrutura de outra representação.

Os resultados desse estudo indicam que a representação social do envelhecimento é a responsável por organizar o conjunto das representações sociais investigadas. Os autores apontam também para a possibilidade de uma relação de conjugação entre duas representações, a saber, envelhecimento e família, estando a primeira subordinada à segunda. Com essa constatação, os autores parecem se afiliarem à possibilidade de relações hierárquicas entre as representações dentro de um sistema.

Em Wachelke (2012) pode ser encontrada um conceito de SRS como um conjunto de representações interconectadas. Contudo, o objetivo deste trabalho ultrapassa o interesse da relação entre representações sociais e a análise atinge o nível das relações entre seus elementos (trabalhados como cognemas). O autor se debruça sobre os efeitos do contexto na ativação relativa a cognemas das representações. Para tanto, explora as relações entre as representações de saúde e de envelhecimento em um estudo experimental, do qual participaram 72 estudantes de uma universidade italiana.

Os resultados desse estudo confirmam a hipótese levantada pelo autor, de que é possível ativar cognemas de duas representações sociais diferentes, desde que os mesmos estejam articulados e as representações integrem um mesmo sistema. Desta forma, o autor conclui que quando pessoas são submetidas a efeitos do contexto ligados a um elemento periférico de uma representação que compõe um sistema, a saliência desta ativação pode estar associada também à ativação de cognemas de outra representação do sistema. Em suas conclusões, Wachelke (2012) também afirma que os resultados desta pesquisa constituem a primeira evidência empírica de relações entre representações sociais no que concerne a cognemas.

Em relação aos trabalhos supracitados (Camargo \& Wachelke, 2010; Wachelke \& Contarello, 2011; e Wachelke, 2012), vale ressaltar a pertinente revisão de literatura que os autores apresentaram acerca do conceito de sistema representacional. Tal revisão se mostrou relevante ao ponto que foi incorporada à introdução deste artigo. Contudo, ressalta-se que as referências apontadas por esses autores não integraram o corpus de análise da presente pesquisa, visto que não estavam disponíveis virtualmente ou indexados 
nas bases de dados consultadas.

Além disso, parecem trabalhar com um conceito de SRS que sofreu alterações com o desenrolar das pesquisas, apresentando uma tendência de análise do SRS a partir de relações cada vez mais "micro", especificamente, entre elementos que compõem as representações. Todavia, esses três trabalhos possuem como pontos em comum a aderência à abordagem estrutural das Representações Sociais, bem como almejam contribuir metodologicamente com investigações empíricas do SRS.

Ainda nessa perspectiva, identificou-se o artigo de Silva, Trindade e Júnior (2012) que, procuraram analisar as representações sociais de conjugalidade em casais separados, apontando, em seus resultados, a constituição de um SRS. Para os autores,

um sistema de representações pode ser entendido como um conhecimento socialmente partilhado formado por um conjunto de objetos representacionais, que, por sua vez, são constituídos por um conjunto de elementos representacionais. Todos os objetos e os elementos representacionais presentes em um sistema representacional estão interrelacionados de tal forma a dar coerência e sentido a esse sistema representacional, como uma rede de significações e símbolos (Silva, Trindade \& Júnior, 2012, p. 441).

Os autores justificam a existência do SRS articulado em volta das representações de conjugalidade pelo fato dos elementos encontrados serem eles próprios, objetos sociais, passíveis de elaborações de representações sociais.

Até agora, os trabalhos apresentados se referem apenas a produções de periódicos. No tocante às teses e dissertações analisadas, destaca-se que essas foram realizadas em dois Programas de Pós-Graduação em Psicologia: um situado na Universidade Federal de Pernambuco (UFPE) e outro na Universidade Federal do Espírito Santo (UFES).

Das sete produções analisadas, seis utilizam o conceito de SRS se referindo a um conjunto de representações, objetos ou temas sociais. Contudo, nesses trabalhos, o conceito é tratado com algumas variações a nível teórico, temático e metodológico.

Correia (2015), a partir de um estudo comparativo com pais de crianças sem e com diagnóstico do transtorno de déficit de atenção e hiperatividade (TDAH), identifica articulações entre as representações sociais do TDAH com outros objetos sociais, como infância, desempenho escolar e doença mental, explorando suas influências mútuas. Felix (2014), que desenvolveu um estudo sobre o cuidado à saúde mental infantil, aponta em seus resultados que, representações de diferentes objetos sociais, como maternidade, autismo e infância, estariam interligados e comporiam um SRS subjacente às práticas de cuidado. Mas, no tocante à proposição teórico-metodológica empregada, a autora lança a proposta de investigação das práticas sociais dos cuidadores frente à criança com demanda em saúde mental para, a partir delas, identificar e analisar suas representações associadas.

Morais (2013) se depara, em seus resultados, com a existência de um SRS no qual as representações sociais de saúde assumiram um lugar central nas relações com outras, como a de hemodiálise (seu objeto de estudo), regulando e articulando elementos na construção das práticas de saúde desse contexto.

Outro autor que se debruçou sobre o estudo das relações entre sistemas de representações e práticas sociais foi Souza (2012), nesse caso, em relação ao alcoolismo. Segundo o autor, na complexidade da vida cotidiana, não se pode conceber que apenas uma representação oriente uma prática, mas que sistemas de representações orientam sistemas de práticas. 
Representações e práticas sobre o alcoolismo e sobre os usuários alcoolistas fazem parte do que se pode chamar de rede de representações ou sistema representacional que inclui outros objetos relevantes para a análise, abordados acima: as Unidades, a Saúde Mental e os usuários em geral (Souza, 2012, p. 530).

Ademais, aponta-se o uso do conceito de SRS (ou sistema representacional) como recurso para discutir e refletir sobre achados empíricos, contribuindo, assim, para a investigação sobre objetos específicos e relevantes socialmente, como prática profissional do psicólogo (Mendes, 2014), alcoolismo (Souza, 2012), saúde mental infantil (Félix, 2014; Correia, 2015) e aposentadoria compulsória (Costa, 2015).

Por fim, pondera-se que algumas dessas produções não apresentam conceituação ou discussão do termo e o conceito de SRS surge apenas na parte referente à análise dos dados, não constando na fundamentação teórica como um conceito de referência ao estudo. Em um destes estudos, o termo surge nos objetivos, mas também não é discutido no decorrer do texto.

\section{SRS como conjunto de conhecimentos}

Em 09 (nove) trabalhos, o SRS parece estar relacionado a determinadas formas ou universos de saberes (sendo mais frequentemente citado a ciência e o senso comum). Refere-se a um conjunto organizado e compartilhado de conhecimentos, informações, saberes e crenças. Essa visão pode ser exemplificada a partir do seguinte trecho: "'Knowledge, understood as a system of representations, is "both dependent upon and expressive of the identity issues experienced by the groups which produce them.' (Gervais \& Jovchelovitch, 1998, citado por Renedo, 2010, p. 02) ${ }^{8}$.

Um trabalho que se destaca nesse sentido é o de Wachelke (2005), cujo objetivo foi apresentar uma hipótese para explicar a recorrência da alteridade como característica da representação social da loucura. Segundo o autor, tal fenômeno é explicado pela existência de um conflito entre sistemas representacionais científicos e culturais, ocasionando uma espécie de vácuo representacional decorrente da ausência de uma compreensão total sobre a loucura por parte dos referidos sistemas. Nas palavras de Wachelke (2005): "O que propomos é considerar que nenhum dos dois sistemas representacionais (ciência e tradição cultural) oferece possibilidade de explicar satisfatoriamente a loucura, enquanto objeto da sociedade" (p. 316). Vale ressaltar que, nessa publicação, o autor trabalha com um conceito distinto daquele apontado em obras mais recentes (Carmargo \& Wachelke, 2010; Wachelke \& Contarello, 2011; Wachelke, 2012).

Embora o autor admita que o conceito de sistemas representacionais não apresenta limites bem definidos, nessa obra, o distingue de uma forma de conhecimento mais ampla. Ou seja, para o autor, o sistema representacional científico seria um conjunto de representações sociais que se ancoram em noções científicas, e não na ciência em si. Do mesmo modo, cada conjunto de crenças culturais é "tratado como um sistema representacional do tipo cultural na medida em que faz sentido por si só para uma dada coletividade" (Wachelke, 2005, p. 318). Dessa forma, nesses trabalhos o conceito de SRS aparece empregado como um corpo ou conjunto de conhecimentos específicos que

\footnotetext{
8 Conhecimento, entendido como um sistema de representações, é 'ambos dependentes e expressivo das questões identitárias vivenciadas pelos grupos que os produzem'." (Gervais \& Jovchelovitch, 1998, citado por Renedo, 2010, p. 02, tradução nossa).
} 
funciona como uma matriz à geração de outros conhecimentos.

\title{
SRS como sinônimo de representações sociais
}

É notório o uso recorrente da noção de SRS sem definição explícita, aproximando-se, por vezes, do próprio conceito de representação social. Nesses casos, 05 trabalhos se referem à abordagem estrutural e as identificações dos sistemas centrais e periféricos, ou tratam a própria representação como um sistema, devido às relações estabelecidas pelos elementos que a compõem.

According to the theory, social representation systems comprise two basic categories, the central nucleus and the periphery elements; the central nucleus is the stable aspect that characterises the references, whilst the peripheral system represents the elements that relate the central nucleus to reality (Veloso-da-Veiga \& Arzate-Salgado, 2013, p. 107) ${ }^{9}$.

Em seu estudo de doutorado, Ceotto (2013) conduz uma pesquisa sobre representações sociais de masculinidade e suas relações com práticas sociais entre jovens e adultos. Seu trabalho foi identificado na busca do Portal de Teses e Dissertações da Capes, entretanto a noção de SRS abordada em seu texto assemelha-se ao próprio conceito de representação social, como se pode observar no seguinte trecho:

\begin{abstract}
Neste sentido, pode-se dizer que uma representação diz respeito à necessidade que cada sujeito, ou até mesmo um grupo de sujeitos, tenha de compreender a situação, ancorando em seus sistemas representacionais objetos novos em consonância com crenças e valores antigos. $O$ que se verifica é que este mesmo sistema de crenças e valores, num primeiro momento, colabora no sentido de explicar esta situação nova (Ceotto, 2013, p. 157-158).
\end{abstract}

\section{Noções dispersas}

Por fim, em 16 (dezesseis) artigos não foi possível estabelecer uma categorização segura, tendo em vista a baixíssima ocorrência do termo no texto (por vezes foi encontrada apenas uma citação), a ausência de definição, a utilização de outro referencial teórico, e/ou, em outros casos, por razão do termo SRS ter sido utilizado para caracterizar outro fenômeno/objeto.

Como exemplo, destaca-se a referência Mitjáns Martínez e González Rey (2006 citado por Lima \& Martínez, 2009, p. 433), cujo sentido de sistema representacional não é explícito, inviabilizando sua classificação nas categorias anteriores:

Além disso, a separação entre os conhecimentos gerados social e individualmente é extraordinariamente frágil, pois em cada momento social de gênese de uma representação aparece um conjunto de sujeitos individuais, cujas criações, contradições e ações são centrais na constituição do núcleo figurativo de um sistema representacional, ao qual ficam subordinados por múltiplos mecanismos de caráter social depois que a representação se apropria do espaço social em que foi engendrada. Este é um processo infinito do desenvolvimento social.

Ademais, identificaram-se trabalhos que se utilizam de autores de outras áreas de conhecimento, como linguística, sociologia e filosofia, para se referirem ao SRS.

\footnotetext{
9 De acordo com a teoria, sistemas de representação social compreendem duas categorias básicas, o núcleo central e os elementos periféricos; o núcleo central é o aspecto estável que caracteriza as referências, enquanto que o sistema periférico representa os elementos que relacionam o núcleo central com a realidade. (Veloso-da Veiga \& Arzate-Salgado, 2013, p. 107, tradução nossa).
} 
Baseado nos pressupostos de Ferdinand Saussure, Hall pontua que o sistema de valores, moralidades, percepções de mundo e conhecimentos que são engendrados pelas representações nos são acessíveis somente por meio dos sistemas de linguagem instituídos (escrita, sons, gestos, imagens, etc.). Nessa perspectiva, as diferentes linguagens se configuram como sistemas de representação que dão a ver os conhecimentos, valores e moralidades, forjados socialmente, que caracterizam uma dada cultura. Desse modo, Hall estabelece um vínculo estreito entre a noção de representação e os campos da comunicação e da cultura (Rocha \& Silva, 2008, p. 165).

Como pode ser observado no trecho seguinte, em alguns trabalhos o termo sistemas representacionais é utilizado para definir outro conceito, como identidade. Nesse sentido, Ben-Asher e Ran Wolf (2014) conceituam identidade como os diversos sistemas de representações sociais que cada indivíduo possui e expressa em seus grupos de pertença.

\begin{abstract}
Identity is defined by means of the social representations shared by the group. Membership in groups whose social representations do not overlap expresses the coexistence of several identities. Consequently, every individual simultaneously holds several social representation systems (identities) that are not necessarily mutually consistent, which can result in contradictory personal choices. At times, for a particular length of time, one group of representations will gain prominence and dominance, while another that represents a different identity, remains in the shadows and does not gain expression (Ben-Asher \& Ran Wolf, 2014, p. 6) ${ }^{10}$.
\end{abstract}

Conforme apontado na figura 2, esta categoria foi a mais expressiva em termos da frequência de trabalhos. Nesse sentido, a opção por apresentá-la por último se justifica pela pouca densidade de conteúdo acerca do conceito de SRS. A partir da revisão aqui apresentada, observou-se que, embora apontada pela literatura como pertinente para a análise de fenômenos sociais complexos, há certa pluralidade de sentidos atribuídos a esse conceito, além de ausência de contornos bem delimitados em termos de nomenclatura, definição e desdobramentos teóricos e metodológicos.

\title{
Considerações finais
}

Com o objetivo de analisar o emprego do conceito de sistemas de representações sociais no âmbito da TRS, nas produções nacionais e algumas internacionais, reitera-se que a pesquisa bibliográfica realizada apontou para uma utilização ainda incipiente, embora em construção. Também foi possível observar certa dispersão de definições sobre o conceito de SRS, bem como sua coadjuvância em diversas publicações. A maioria dos trabalhos analisados não possuía o conceito de SRS como objeto ou tema de estudo, nem tampouco se propunha a tecer aprofundamentos sobre o mesmo, do ponto de vista teórico e/ou metodológico. Assim sendo, apesar de polissêmico, o termo emergia com baixa frequência e destaque nos textos.

É notório, entretanto, que alguns trabalhos se diferenciam pela centralidade que o conceito de SRS assume. Nesse sentido, destacam-se as produções de alguns pesquisadores que elegeram a análise de SRS como objetivos de seus estudos, dentre os quais, Wachelke (2005; 2012), Camargo e Wachelke (2010), Wachelke e Contarello (2011), Silva, Trindade e Junior (2012), Félix (2014), Correia (2015), dentre outros. Alguns desses trabalhos

\footnotetext{
10 Identidade é definida por meio das representações sociais compartilhadas pelo grupo. Participação em grupos cujas representações sociais não se sobreponham expressa a coexistência de várias identidades. Consequentemente, cada indivíduo detém simultaneamente vários sistemas de representação social (identidades) que não são necessariamente coerentes entre si, o que pode resultar em escolhas pessoais contraditórias. Às vezes, por um período específico de tempo, um grupo de representações vai ganhar destaque e dominância, enquanto outro que representa uma identidade diferente, permanece nas sombras e não ganha expressão (Ben-Asher \& Ran Wolf, 2014, p.6, tradução nossa).
} 
demonstram um esforço em problematizar o conceito de SRS, embora a partir de distintas abordagens. Em tais produções averiguou-se que o uso do conceito de SRS como conjunto de representações sociais prevaleceu. Nesse sentido, ainda se observou diferenciações no conceito, visto que alguns trabalhos, além de considerar a existência de representações sociais articuladas, também consideram e analisam a existência de relações hierárquicas entre essas.

Um aspecto que se destaca nessa pesquisa bibliográfica, versa sobre a ausência de trabalhos que se refiram à discussão de sistema e metassistema proposta por Moscovici (1961/2012) e, posteriormente por Doise (2011). Apenas uma dissertação analisada (Costa, 2015) faz referência a esses conceitos em sua fundamentação teórica. Assim, reflete-se que tais conceitos poderiam ser úteis na problematização e discussão de SRS.

Ademais, percebeu-se que as publicações da revista Papers on Social Representation se diferenciam em termos quantitativos e qualitativos. Isto é, o número de artigos advindos dessa revista foi mais expressivo em comparação com as outras bases de dados consultadas (tal como apontado no método). Além disso, a quase totalidade das produções que se propuseram a abordar o conceito de SRS no sentido teórico-metodológico foi localizada nessa fonte. Os resultados ratificam, assim, a importância desse periódico na construção e consolidação da TRS.

Pode-se refletir que algumas características das ferramentas de busca disponíveis nas bases de dados implicaram em dificuldades na coleta dos documentos e limitações para o presente estudo. Ao inserir os termos para os quais se deseja realizar a busca no Banco de Teses e Dissertações da Capes, são localizados apenas os trabalhos que possuírem os termos em seus títulos, resumos ou palavras-chaves, excluindo assim, os trabalhos que porventura os incluam em outras sessões. Também se destaca a limitação que diz respeito à inclusão de trabalhos nessa base de dados, tendo em vista que as publicações mais recentes que estão disponíveis datam do ano de 2012. Na busca dos periódicos também foram encontrados empecilhos, principalmente no que versa sobre os filtros para os termos utilizados. Por vezes, mesmo utilizando recursos como buscar palavra exata ou o comando de busca entre aspas ("')), eram indicados trabalhos que não condiziam com a busca solicitada (como aponta a limpeza dos dados indicada na seção de método). Ademais, atenta-se para a importância dos autores interessados em discutir o conceito de SRS começarem a utilizar o termo "sistema de representações sociais", "sistemas representacionais" e demais variações como palavras-chaves de seus trabalhos, de modo a favorecer a localização dos mesmos.

Por fim, reforça-se a necessidade de mais estudos sobre o conceito, necessidade esta explicitada pela maioria dos estudos analisados, sobretudo no que se refere à compreensão sobre os processos de construção das representações sociais acerca dos objetos sociais imbricados no sistema e suas relações. Ademais, é necessário atentar-se para a sua diferenciação e caracterização, uma vez que, quando presente, o termo por vezes não é apresentado com clareza e confunde-se com outros. Considera-se que contribuições podem ser feitas no sentido de elucidar o(s) modo(s) como os sistemas representacionais se caracterizariam e se constituiriam. Além disso, pode-se refletir sobre as implicações que o olhar sobre o(s) objeto(s), a partir do ponto de vista de SRS, pode acarretar na compreensão dos fenômenos sociais estudados. 


\section{Referências}

Abric, J-C. (1998). A Abordagem Estrutural das Representações Sociais. In A. S. P. Moreira \& D. C. de Oliveira (Orgs.). Estudos Interdisciplinares de Representação Social (pp. 27-38). Goiana: AB Pesquisa.

Almeida, A. M. O. (2009). Abordagem Societal das Representações Sociais. Sociedade e Estado, Brasília, 24(3), 713-737.

Almeida, A. M. O. (2005). A Pesquisa em Representações Sociais: Proposições teórico-metodológicas. In M. F. S. Santos \& L. M. Almeida (Orgs.). Diálogos com a Teoria da Representação Social (pp. 117-160). Recife: EDUFPE/EDUFAL

Almeida, A. M. O. (2001). A pesquisa em representações sociais: fundamentos teórico-metodológicos. Ser Social, Brasília, 9(1),129-158,

Arruda, A. (2009). Meandros da teoria: a dimensão afetiva das representações sociais. In A. M. O. Almeida \& D. Jodelet (Orgs.) Representações sociais: interdisciplinaridade e diversidade de paradigmas (pp. 83-102). Brasília: Thesaurus Editora.

Bardin, L. (1977/2011). Análise de conteúdo. Lisboa: Edições 70.

Ben-Asher, S. \& Wolff, R. (2014). Privacy as a Social Mechanism for Maintaining Inconsistency Between Identities. Papers on Social Representations, 23(11), 1-11.22. Recuperado de http://psych1.Ise.ac.uk/psr/PSR2014/2014_1_11.pdf.

Breakwell, G. M. (1993). Social representations and social identity. Papers on social representations, 2(3), 198217. Recuperado de http://www.psr.jku.at/PSR1993/2_1993Brea2.pdf.

Camargo, B. \& Wachelke, J. (2010). The study of social representacions systems: Relashionships involving representacions on aging, AIDS and the body. Papers on Social Representations, 19, 21.1-22.1. Recuperado de http://laccos.com.br/pdf/Camargo_Wachelke2010.pdf.

Ceotto, E. C. (2013). De Jonh Wayne a David Beckham - resignificações das masculinidades: um estudo em Representações Sociais. Tese de Doutorado, Universidade Federal do Espírito Santo, Vitória, Espírito Santo, Brasil.

Codol, J. P. (1984). On the system of representations in an artificial social situation. In R. Farr \& S. Moscovici (Orgs.). Social representation (pp. 239-253). Cambridge: University Press.

Correia, C. C. G. (2015). Transtorno de Déficit De Atenção/Hiperatividade e Representações Sociais: A construção dos saberes por pais de crianças em idade escolar. Dissertação de Mestrado, Universidade Federal de Pernambuco, Recife, Pernambuco, Brasil.

Costa, F. J. F. N. (2015). Envelhecimento - Trabalho - Identidade: um estudo sobre aposentadoria compulsória através da Teoria das Representações Sociais. Dissertação de Mestrado, Universidade Federal de Pernambuco, Recife, Pernambuco, Brasil.

Doise, W. (2011). Sistema e metassistema. In A. M. O Almeida, M. F. S Santos \& Z. A. Trindade (Org.). Teoria das Representações Sociais: 50 anos (pp. 123-156). Brasília: Technopolitik.

Félix, L. (2014). O cuidado à saúde mental na infância: Entre práticas e representações sociais. Dissertação de Mestrado, Universidade Federal de Pernambuco, Recife, Pernambuco, Brasil.

Garnier, C. (1999). La genèse des représentations sociales dans une perspective développementale. In M. L. Rouquette \& C. Garnier (Eds.). La genèse des représentations sociales (pp. 87-113). Montreal, Canada: Nouvelles.

Glăveanu, V. P. (2009). What differences make a difference?: a discussion of hegemony, resistance and representation. Papers on social representations, 18(2), 1-2.22. Recuperado de http://eprints.Ise.ac.uk/39033/1/What_Differences_Make_A_Difference_A_Discussion_of_Hegemony, Resistance_and_Representation_(Isero).pdf.

Jodelet, D. (2011). Sobre o ponto de vista: movimento das representações sociais comunidade científica brasileira. Temas em Psicologia, 19(1), 19-26. Recuperado de http://pepsic.bvsalud.org/scielo.php?pid=S1413-389X2011000100003\&script=sci_arttext. 
Jodelet, D. (2001) Representações Sociais: um domínio em expansão. In D. Jodelet (Org.) As Representações Sociais (pp. 17-44). Rio de Janeiro: Eduerj.

Jovchelovitch, J. (2007). Os contextos do saber, representação, comunidade e cultura. Petrópolis: Editora Vozes.

Lima, B. J. \& Martínez, A. M. (2009). A Zona Muda das Representações Sociais: Uma Aproximação a Partir do Jogo de Areia. Revista Interamericana de Psicología/Interamerican Journal of Psychology, 43(3), 432441. Recuperado de http://www.psicorip.org/Resumos/PerP/RIP/RIP041a5/RIP04346.pdf.

Lima, T. C. S. \& Mioto, R. C. T. (2007) Procedimentos metodológicos na construção do conhecimento científico: a pesquisa bibliográfica. Rev. Katál. Florianópolis, 10(n. esp.), 37-45. Recuperado de http://www.scielo.br/scielo.php?pid=S1414-49802007000300004\&script=sci_arttext.

Mendes, F. M. S. (2014). A representação social de prática profissional para psicólogos clínicos da Grande Vitória/ES. Dissertação de Mestrado, Universidade Federal do Espírito Santo, Vitória, Espírito Santo, Brasil.

Morais, E. R. C. (2013). Saúde e Tratamento Hemodialítico: Representações Sociais em um Serviço de Terapia Renal Substitutiva. Dissertação de Mestrado, Universidade Federal de Pernambuco, Recife, Pernambuco, Brasil.

Moscovici, S. (1961/2012). A psicanálise, sua imagem e seu público. Petrópolis: Vozes. (Trad. de Sonia Fuhrmann).

Moscovici, S. (1984/2012). Prefácio. In P. Guareschi \& S. Jovchelovitch (Org.) Textos em representações sociais (pp. 07-15). Petrópolis: Editora Vozes.

Moscovici, S. (2003). O fenômeno das representações sociais. In S. Moscovici \& G. Duveen (Orgs.) Representações sociais: investigações em psicologia social (pp. 29-214). Petrópolis: Vozes.

Moscovici, S. (2009). Representações Sociais: Investigações em psicologia social (6a ed.). Petrópolis: Vozes.

Renedo, A. (2010). Polyphony and Polyphasia in Self and Knowledge. Papers on Social Representation, 19, 12.112.21. Recuperado de http://www.psych.Ise.ac.uk/psr/PSR2010/19_12Renedo.pdf.

Rocha, S. \& Silva, V. (2008). Absoluts x Adbusters: vínculos sociais da publicidade revelados pela antipublicidade. Comunicação, mídia e consumo, 5(13), 159-179. Recuperado de http://revistacmc.espm.br/index.php/revistacmc/article/view/131/132

Sá, C. P. De. (1998). A construção do objeto de pesquisa em representações sociais. Rio de Janeiro: Ed. UERJ.

Santos, M. F. S. (2011). Compreendendo sistemas de representação: a família como exemplo. Projeto de pesquisa aprovado pelo CNPQ, 2011.

Santos, M. F. S. (2005). A teoria das representações sociais. In M. F. S. Santos \& L. M. Almeida. Diálogos com a teoria das representações sociais (pp. 13-38). Recife: EDUFPE/EDUFAL.

Santos, M. F. S (2009). Representações sociais e psicologia social. In A. M. O. Almeida \& D. Jodelet (Orgs.). Representações sociais: interdisciplinariedade e diversidade de paradigmas (pp. 51-82). Brasília: Thesaurus Editora.

Santos, M. F. S., Novelino, A. M. \& Nascimento, A. P. (2001). O mito da maternidade: discurso tradicional sob roupagem modernizante? In A. S. P. Moreira (Org.) Representações Sociais: Teorias e Práticas (pp. 269293). João Pessoa: EDU.

Santos, M. F. S., Morais, E. R. C. \& Acioli Neto, M. L. (2012), A Produção Científica em Representações Sociais: análise de dissertações e teses produzidas em Pernambuco. Revista Psico, 43(2), 200-207. Recuperado de http://revistaseletronicas.pucrs.br/ojs/index.php/revistapsico/article/view/11697/8043.

Santos, M. F. S., Andrade, D. A., Morais, E. R. C., Félix, L. B., Acioli Neto, M. L. \& Sousa, Y. S. O. (2013). An overview on Social Psychology in Brazil: theoretical contributions from the production of journals. Estud. psicol. (Natal), 18(1), 17-23.

Scoz, B. J. L. \& Martinez, A. M. A (2009). Zona Muda das Representações Sociais: Uma Aproximação a Partir do Jogo de Areia. Revista Interamericana de Psicología, 43(3), 432-441. Recuperado de http://www.psicorip.org/Resumos/PerP/RIP/RIP041a5/RIP04346.pdf.

Silva, P. O. M., Trindade, Z. A. \& Silva Junior, A. (2012). As representações sociais de conjugalidade entre casais 
recasados. Estudos de Psicologia, 17(3), 435-443.

Souza, L. G. S. (2012). Profissionais de saúde da família e representações Sociais do alcoolismo. Tese de Doutorado, Universidade Federal do Espírito Santo, Vitória, Espírito Santo, Brasil.

Trindade, Z. A., Santos, M. F. S. \& Almeida, A. M. O. (2011). Ancoragem: notas sobre consensos e dissensos. In A. M. O. Almeida, M. F. S. Santos \& Z. A. Trindade (Org.). Teoria das representações sociais 50 anos (pp. 101-122). Brasília: Techno Politik Editoras.

Veloso-da-Veiga, C. \& Arzate-Salgado, J. (2013). Mexican and Portuguese young students facing disability. Convergencia Revista de Ciencias Sociales, 63, 99-124. Recuperado de http://convergencia.uaemex.mx/article/viewFile/1022/753.

Wachelke, J. F. R. (2005). O vácuo no contexto das representações sociais: uma hipótese explicativa para a representação social da loucura. Estudos de Psicologia (Natal), 10(2), 313-320. Recuperado de http://www.scielo.br/scielo.php?script=sci_arttext\&pid=S1413-294X2005000200019.

Wachelke, J. F. R. (2011). Structural relationships among social representations: cognem associations within a representational system. Tese de Doutorado, Università degli Studi di Padova. Padova, Itália.

Wachelke, J. \& Contarello, A. (2011). Italian students' social representations on aging: an exploratory study of a representational system. Psicologia: Reflexão e Crítica (UFRGS. Impresso), 24, 551-560. Recuperado de http://www.scielo.br/scielo.php?script=sci_arttext\&pid=S0102-79722011000300016.

Wachelke, J. (2012). Context effects and inter-representation activation: an experimental study. Papers on Social Representations, 21, 8.1-8.28. Recuperado de http://psych1.Ise.ac.uk/psr/PSR2012/2012_1_8.pdf.

Wachelke, J., Matos, F. R., Ferreira, G. C. S. \& Costa, R. R. de L. (2015). Um panorama da literatura relacionada às representações sociais publicada em periódicos científicos. Temas em Psicologia, 23(2), 309-325. Recuperado de http://pepsic.bvsalud.org/scielo.php?pid=S1413389X2015000200005\&script=sci_arttext. 